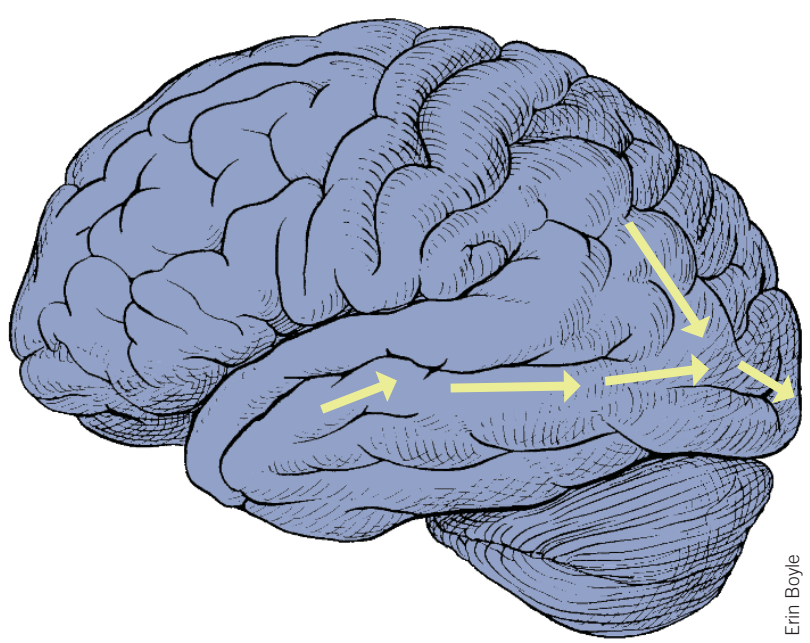

Figure 1 In sighted people, the visual cortical hierarchy begins with V1, but in the blind, this cortical territory is used for verbal memory, which is normally the task of higher brain areas.

like oriented lines, whereas neurons in higher tier areas like LOC respond to more complex stimulus aspects such as objects, irrespective of their size or orientation. According to this concept, areas involved in verbal processing should be placed high up in the hierarchy, given the complexity of verbal material. However, exactly the opposite was observed in this study. Some of the most complex functions (verbal memory and verb generation) were located in a primary sensory area, V1. This turns the hierarchical organization of the occipital lobe on its head (Fig. 1).

It seems that the functional hierarchy of the occipital cortex is not carved in stone, but rather represents the result of normal development under certain constraints (e.g., visual input to V1 from the thalamus). However, if visual input is absent during development, a different form of functional hierarchy can arise. In this new architecture, V1 seems to become a higher-tier area. The pruning of abundant connections during development might be the mechanism that determines whether $\mathrm{V} 1$ receives its dominant input from the LGN or other cortical areas. This explanation suggests that only people blind from birth-those who are deprived of visual input during the development of the visual systemshould have the capacity to organize their occipital cortex in this way and thus have superior verbal memory abilities. This fits with observations that congenitally blind people show particularly improved verbal memory function.

Continuing this line of speculation, one might also expect a different cytoarchitecture in the primary visual cortex in congenitally blind subjects as a result of this reorganization, as has been demonstrated in non-human primates ${ }^{11}$. Reducing thalamic fibers projecting into primary visual cortex in monkeys during development caused a cytoarchitectonically new area to emerge within primary visual cortex. The cytoarchitectonic properties of this area not only differed from those of primary visual cortex (area 17) but also from those of the extrastriate visual area (area 18). Whether this transformation of the occipital cortex also occurs in congenitally blind people may be clarified by future post-mortem investigations.

1. Sadato, N. et al. Nature 380, 526-528 (1996). 2. Büchel, C., Price, C. \& Friston, K. Nature 394, 274-277 (1998)

3. Röder, B., Rösler, F. \& Neville, H.J. Cogn. Brain Res. 11, 289-303 (2001).

4. Amedi, A., Raz, N., Pianka, P., Malach, R. \& Zohary, E. Nat. Neurosci. 6, 758-766 (2003).

5. Büchel, C., Price, C., Frackowiak, R.S.J. \& Friston, K. Brain 121, 409-419 (1998).

6. Amedi, A., Malach, R., Hendler, T., Peled, S. \& Zohary, E. Nat. Neurosci. 4, 324-330 (2001).

7. Burton, H., Snyder, A.Z., Diamond, J. \& Raichle, M.E. J. Neurophysiol. 88, 3359-3371 (2002).

8. Wanet Defalque, M.C. et al. Brain Res. 446, 369-373 (1988)

9. Hamilton, R.H. \& Pascual-Leone, A. Trends Cogn. Sci. 2, 168-174 (1998).

10. Ungerleider, L.G. \& Haxby, J.V. Curr. Opin. Neurobiol. 4, 157-165 (1994).

11. Rakic, P., Suner, I. \& Williams, R.W. Proc. Natl. Acad. Sci. USA 88, 2083-2087 (1991).

\title{
Watching the brain learn to read
}

Children start to read by rote recognition of words based on visual features or context; for example, the word 'stop' appears in a red octagonal sign. Older children progress to using phonetic cues to decode words. Literate adults process words in clusters, and identify unknown words by analogy to known ones. In this issue (pages 767-773), Guinevere Eden and colleagues report discrete changes in brain activity, measured by functional magnetic resonance imaging, that correlate with these developmental changes in reading strategies. Areas of the brain involved in mapping print to sound were found to mature early in learning, and continued to be involved in reading through adulthood; other areas involved in semantic and phonological processing also increased their activity with reading ability. In contrast, as reading ability progressed, activity decreased in regions of the brain thought to be involved in form recognition, possibly reflecting proficient readers' greater reliance on text as opposed to visual context.

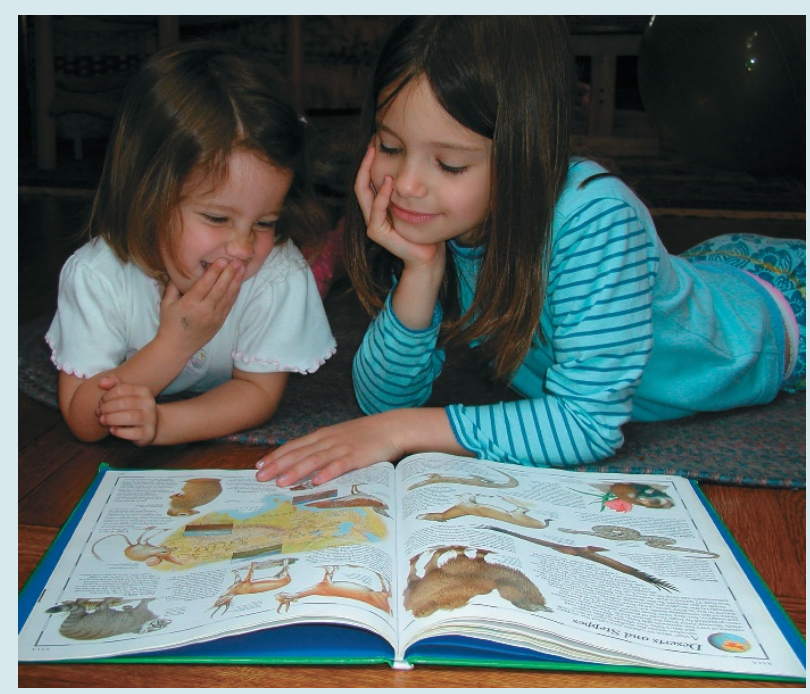

\section{John Spiro}

